\title{
Monetary Policy Rules for an Open Economy
}

\author{
Nicoletta Batini* \\ Richard Harrison** \\ and \\ Stephen P. Millard* \\ First draft: December 1999 \\ This draft: May 2000 \\ Preliminary and Incomplete \\ (Please do not quote without the authors' permission)
}

\begin{abstract}
The most popular simple rules for the interest rate, due to Taylor (1993a) and Henderson and McKibbin (1993), are both meant to inform monetary policy in economies that are closed. On the other hand, their main open economy alternatives, based on a Monetary Conditions Index (MCI) are potentially flawed for a number or reasons, not least because they fail to adequately allow for different types of exchange rate shocks when setting policy. In this paper we derive simple monetary policy rules that are suitable for small open economies in general, and for the UK in particular. We do so by comparing the performance of a battery of complex and simple rules, including the familiar Taylor and Henderson and McKibbin rules and MCI-based rules. This entails comparing the asymptotic properties of a two-sector open-economy dynamic stochastic general equilibrium model calibrated on UK data under different rules. We find that a good simple rule is one that responds to changes in the real exchange rate in addition to output and inflation. This does not imply having a target on the exchange rate, but rather suggests that it may be useful to exploit its indicator properties in the pursuit of domestic objectives.
\end{abstract}

* Research Adviser, MPC Unit, Bank of England, Threadneedle Street, London EC2R 8AH, United Kingdom. Tel: +44 20 76014354. Fax: +44 2076013550

E-mail: nicoletta.batini@bankofengland.co.uk (corresponding author)

** Analyst, Monetary Assessment and Strategy Division, Monetary Analysis, Bank of England, Threadneedle Street, London EC2R 8AH, United Kingdom.

Tel: +44 20 76015662. Fax: +44 20 76014177. E-mail: richard.harrison@bankofengland.co.uk

* Manager, Monetary Instrument and Markets Division, Monetary Analysis, Bank of England, Threadneedle Street, London EC2R 8AH, United Kingdom.

Tel: +44 20 76014115. Fax: +44 20 76014177. E-mail: stephen.millard@bankofengland.co.uk

We thank Nicola Anderson, Spencer Dale, Shamik Dhar, Rebecca Driver, Chris Erceg, Neil Ericsson, Jeff Fuhrer, Andy Levin, Bennett McCallum, Katherine Neiss, Edward Nelson, Glenn Rudebusch, Chris Salmon, Anthony Yates and seminar participants at the Bank of England for useful comments on earlier versions of this paper. Remaining errors, and the views expressed herein are those of the authors and not of the Bank of England nor of the Bank of England's Monetary Policy Committee. 
1. Introduction 3

2. A two-sector open-economy optimising model 5

2.1 Preferences and government policy 6

$\begin{array}{ll}2.2 \text { Technology } & 9\end{array}$

2.2.1 Export Sector Firms $\quad 10$

2.2.2 Non-Traded-Goods Sector Firms 10

2.3 Goods' Market Equilibrium 11

2.4 The transmission mechanism 11

2.5 The balance of payments $\quad 12$

3. Model solution and calibration 13

3.1 Solving the model 13

$\begin{array}{ll}3.2 \text { Calibration } & 14\end{array}$

$\begin{array}{ll}\text { 4. } & \text { Properties of the model } \\ & 18\end{array}$

5. Results: a comparison of simple rules 23

5.1 A battery of rules 25

$\begin{array}{ll}5.2 \text { Results } & 30\end{array}$

5.3 Sensitivity analysis 33

5.4 Robustness analysis $\quad 35$

$\begin{array}{ll}\text { 6. Conclusions } & 38\end{array}$

Technical Appendix 


\section{Introduction}

To date, the literature on simple rules for monetary policy is vast. ${ }^{1}$ It contains theoretical research comparing rules that respond to alternative intermediate and final targets, backwardand forward-looking rules, and finally, rules which include or exclude interest rate smoothing terms. It also contains work on historical estimates of monetary policy rules for various countries.

However, the literature does not contain a thorough analysis of simple rules for open economies, i.e. for economies where the exchange rate channel of monetary policy plays an important role in the transmission mechanism. The most popular simple rules for the interest rate — due to Taylor (1993a) and Henderson and McKibbin (1993) — for example, were both designed for the United States and, thus, on the assumption that the economy is closed. And the main open economy alternatives, i.e. the rules based on a Monetary Conditions Index (MCI), are potentially flawed because they do not account for different types of exchange rate shocks. So at present we only have a choice of ignoring the exchange rate completely (Taylor, Henderson and McKibbin) or including it in an unsatisfactory way (MCIbased rules).

In this paper we derive a simple monetary policy rule ('BHM rule', hereafter) that stabilizes inflation and output in small open economies at a lower social cost than the existing rules. It does this by augmenting in a parsimonious way alternative closed-economy rules in order to account explicitly for the exchange rate, expectations-based channel of monetary transmission. We compare the performance of this rule to that of a battery of alternative rules when the model economy is buffeted by various shocks. The alternatives we consider include the Taylor and Henderson and McKibbin closed-economy rules, MCI-based rules and inflation forecast-based rules. The BHM rule appears to be robust across a set of different shocks, including shocks to the domestic economy from the rest of the world, contrary to closed-economy rival simple rules, which ignore the exchange rate channel of monetary transmission.

\footnotetext{
${ }^{1}$ See Bryant et al (1993) and Taylor (ed.) (1999).
} 
To test the rules, we stylise the economy — that we calibrate to UK data — as a two-sector open-economy dynamic stochastic general equilibrium model. The export/non-traded sector split is important because it allows us to discern different impacts of the same shock on output and inflation in the two sectors. Identification of sectoral inflation and output dynamics is a key element on which to base the design of efficient policy rules. More generally, it also makes it possible for the monetary authority to ponder the costs of price stabilization on each sector of the economy.

Because it is theoretically derived on the assumption that consumers maximise utility and firms maximise profits, the model has a rich structural specification. This enables us to contemplate shocks that could not be analysed in less structural or reduced form small macro-models.

In particular, with our model, we can examine the implications of shocks to aggregate demand such as a shock to households' preferences, or a shock to the rest of the world's income. On the supply side, we can consider shocks to the overseas price level. We can analyse the impact of a relative productivity shock on the two sectors and investigate how this affects the real exchange rate by altering the price of the non-tradables relative to export goods. We can also look at the effects of a change in the price of imported intermediate goods. We can examine the effects of shocks to the foreign exchange risk premium in the Uncovered Interest Parity equation. Finally, we can look at the implications of a monetary policy shock, both home and abroad.

The ability to examine all these different shocks is important when comparing alternative policy rules for an open economy, because the efficient policy response to changes in the exchange rate will typically depend on what shock has hit the economy — with different shocks sometimes requiring opposite responses. For this purpose our small economy general equilibrium model is sufficient. A two-country model would enable us to look at these same shocks, but would rule out the small-economy assumption - which we believe is realistic for the UK — and add unnecessary complexity to the analysis. 
In short, this model is well suited to our analysis for three reasons. First it is a structural, theoretically based model. The structural nature of the model is important because it guarantees that our policy analysis (i.e. comparison of different rules/regimes) is immune to the Lucas critique. Second, it offers a more disaggregated picture of the economy. This allows us to identify the different dynamics of output and inflation after a shock - a valuable input to the efficient design of rules. Third, because it is structural and built from micro-principles, it allows us to consider shocks (such as preference or relative productivity shocks) which are key for the design of a rule meant to be a 'horse for all courses' in an open economy setting.

The rest of the paper is organised as follows. In section 2 we lay out the model that we employ throughout to derive the efficient open-economy simple rule and describe its steady state properties. The solution and calibration of the model are discussed in section 3 . In section 4 we study some properties of the model. In section 5 we specify the efficient open economy simple rule and present results comparing the stabilisation properties of this rule against those of a battery of alternative simple rules, in the face of various disturbances. Finally, section 6 concludes. We close the paper with a Technical Appendix that gives further details about the model's non-linear and log-linear specification.

\section{A two-sector open-economy optimising model}

The model we use is a calibrated small-scale structural rational-expectations model of the UK economy with a sectoral split between exported and non-tradeable goods. Its specification draws on the literature on open-economy optimising models by Svensson and van Wijnbergen (1989), Correia, Neves and Rebelo (1994), Obstfeld and Rogoff (1996), and more recent work by McCallum and Nelson (1999). However, it extends upon these (and other closed-economy optimising models), by introducing several novel features that are described in detail below.

The model describes an economy that is 'small' with respect to the rest of the world. In practice, this means that the supply of domestically produced traded goods does not affect the price of these goods internationally. It also means that the price of imported foreign 
goods, foreign interest rates and foreign income are exogenous in this model, rather than being endogenously determined in the international capital and goods markets, as would happen in a multiple-country, global-economy model. This assumption considerably simplifies our analysis; and because we are not interested here in studying either the transmission of economic shocks across countries or issues of policy interdependence, it comes at a relatively small price.

As we are interested in evaluating alternative monetary policy rules, we specify monetary policy within the model as a rule for the nominal interest rate (the policy instrument). We look at alternative rules in the attempt to see whether responding to some 'open-economy' variables (such as the exchange rate or the balance of trade) can improve the stabilisation properties of rules designed for a closed economy context, and thus, responding only to output and inflation.

\subsection{Preferences and government policy}

Our economy is populated by a large number of identical households. For simplicity, we imagine that the size of the population is constant. ${ }^{2}$ Each household is assumed to live forever and to have identical preferences defined over consumption of a basket of tradable and nontradable goods, leisure and real money balances at every date. Preferences are additively log-separable and imply that every household's objective is to maximise:

$$
E_{0} \sum_{t=0}^{\infty} \beta^{t}\left(\exp \left(v_{t}\right) \ln \left(c_{t}-\xi_{c} c_{t-1}\right)+\delta \ln \left[\left(1-h_{t}\right)-\xi_{h}\left(1-h_{t-1}\right)\right]+\frac{\chi}{1-\varepsilon}\left(\frac{\Omega_{t}}{P_{t}}\right)^{1-\varepsilon}\right)
$$

where $0<\beta<1 ; \delta, \chi$ and $\varepsilon$ are restricted to be positive and $E_{0}$ denotes the expectation based on the information set available at time zero. In equation (1), $c_{t}$ is total time $t$ per capita real consumption, $v_{t}$ is a white noise shock to preferences - essentially an demand shock, described in more detail in sections 3 and $4-$ and $h_{t}$ is labour supplied to market activities, expressed as a fraction of the total time available. So the term $\left(1-h_{t}\right)$ captures the utility of time spent outside work. The last term $\Omega_{t} / P_{t}$ represents the flow of transaction- 
facilitating services yielded by real money balances during time $t$ (more on this later). Hence here, as in the standard Sidrauski-Brock model, money enters the model by featuring directly in the utility function.

In addition, since $\xi_{c}$ and $\xi_{h} \in[0,1)$, preferences over consumption and leisure encompass habit formation, with the functional form used in (1) similar to that of Carrol et al. (1995) and Fuhrer (2000). This implies that preferences are not time-separable in either consumption or in leisure, so that households' utility depends not only on the level of consumption and leisure in each period, but also on their level in the previous period. ${ }^{3}$

Total consumption, meanwhile, is obtained by aggregating the consumption of imported tradable and non-tradable goods $c_{M, t}$ and $c_{N, t}$ via the geometric combination $c_{t}=c_{M, t}^{\gamma} c_{N, t}^{1-\gamma}$, where $\gamma \in(0,1){ }^{4}$ However, whereas in this economy there is only one tradable good, we assume that there are many differentiated non-tradable goods, which we combine using the Dixit-Stiglitz (1977) aggregator $c_{N, t}=\left(\int_{0}^{1} c_{t}(j)^{\frac{\theta-1}{\theta}} d j\right)^{\frac{\theta}{\theta-1}}$ (where $\theta$ is the elasticity of substitution between varieties of non-traded goods). ${ }^{5}$ Then we can define a consumptionbased price deflator, $P_{t}=\frac{P_{M, t}^{\gamma} P_{N, t}^{1-\gamma}}{\gamma^{\gamma}(1-\gamma)^{1-\gamma}}$ equal to an aggregate of tradable and non-tradable goods' prices, $P_{M, t}$ and $P_{N, t}$, respectively.

\footnotetext{
${ }^{2}$ We normalise this constant to unity, for convenience.

${ }^{3}$ The assumption that wages are perfectly flexible in this model and that, hence, the labour market constantly clears, imply that 'habit formation in leisure' involves some kind of 'addiction to leave time', rather than to being unemployed or else 'contagious laziness', as would be in the presence of unemployment. In part, this assumption is rationalised in Fuhrer (op cit.), who found strong evidence of habit formation in consumption of goods for the US; he showed that, once accounted for, this can improve the ability of optimising models of consumer behaviour to replicate the output dynamics observed in the data. Since, in principle, there is no reason why the persistent behaviour in spending patterns should not carry over to leisure - which is also treated as a good in similar such optimising models - here we generalise Fuhrer's (op cit.) approach to allow for habit formation in leisure.

${ }^{4}$ We have assumed that domestically produced tradeable goods are not consumed by domestic consumers, ie are all exported. Hence, when talking about consumption we use the superscript, $T$, to denote 'imported traded goods', whereas when talking about production we use the superscript, $X$, to denote 'exported goods'.

${ }^{5}$ The assumption of two types of good, rather than a single consumption index, differentiates this model from the more stylised approaches used, for example, in Obstfeld and Rogoff (op cit.) or McCallum and Nelson (op cit.).
} 
Each household has access to a domestic and a foreign nominal bond market at the interest rates $i$ and $i_{f}$, respectively. For the time being, we assume that both kinds of bond are riskless. Money is introduced into the economy by the government. Since Ricardian equivalence holds in this model we can assume without loss of generality a zero net supply of domestic bonds. Then the public sector budget constraint requires that all the revenue associated with money creation must be returned to the private sector in the form of lumpsum transfers in each period:

$$
M_{t}-M_{t-1}=T_{t}
$$

where $M_{t}$ is end-of-period $t$ nominal money balances, and $T_{t}$ is a nominal lump-sum transfer received from the home government at the start of period $t$.

The household's dynamic budget constraint in each period is given by equations (3) and (4) below, where $M_{t-1}$ is nominal money balances at time $t-1 ; B_{t-1}$ and $B_{f, t-1}$ are time $t-1$ holdings of domestic and foreign bonds, respectively; $D_{t}$ are dividends from shares held in firms in the two sectors; $e_{t}$ is the nominal exchange rate expressing foreign currency in terms of units of domestic currency; ${ }^{6}$ and finally, $W_{t}$ is the nominal wage.

$$
\begin{aligned}
& M_{t}+B_{t}+\frac{B_{f, t}}{e_{t}}=M_{t-1}+\left(1+i_{t-1}\right) B_{t-1}+\left(1+i_{f, t-1}\right) \frac{B_{f, t-1}}{e_{t}}+W_{t} h_{t}+D_{t}+T_{t}-P_{t} c_{t} \\
& \Omega_{t}=M_{t-1}+T_{t}+\left(1+i_{t-1}\right) B_{t-1}+\left(1+i_{f, t-1}\right) \frac{B_{f, t-1}}{e_{t}}-B_{t}-\frac{B_{f, t}}{e_{t}}
\end{aligned}
$$

Equation (3) describes the evolution of nominal wealth. Equation (4) defines the nominal balances available to consumers to spend at time $t$. This reflects the assumption that consumers participate in the financial markets before spending money on goods and services. As suggested by Carlstrom and Fuerst (1999), entering money balances as defined in (4) in the utility function, gives a better measure of period utility; one in which we account

\footnotetext{
${ }^{6}$ So that an increase in $e_{t}$ represents an appreciation of the domestic currency.
} 
exclusively for the services of balances that are actually available to households when spending decisions are taken.

\subsection{Technology}

Firms in our model are of two kinds: firms that produce a single good for export and act competitively; and firms that produce non-traded goods and act monopolistically. There is no capital in the model. Both types of firms employ a Cobb-Douglas production function technology, using labour supplied by the households (labelled $h_{X, t}$ and $h_{N, t}$, to distinguish the hours of labour hired by the export and the non-traded sector, respectively) and an intermediate good imported from abroad as factors of production (hereafter labelled $I_{X, t}$ and $I_{N, t}$, to distinguish the quantities of imported input purchased by the export and the nontraded sector, respectively). Each sector faces an exogenous technology shock, $A_{Z, t}$ hereafter (where $Z$ is either ' $N$ ' or ' $X$ ' to denote a shock to the non-traded and export sectors, respectively). Under perfect competition, $\alpha_{Z}$ and $\left(1-\alpha_{Z}\right)$ are the shares of labour and the intermediate imported good, respectively used for the production of $y_{Z, t}$, and these are allowed to differ across sectors.

We assume that the labour market is perfectly competitive. We also assume that firms behave competitively in the intermediate goods markets. Under Purchasing Power Parity, the price that domestic producers would pay for these goods $\left(P_{I, t}\right)$, adjusted for the exchange rate, would always be determined on the global market. To capture the empirical sluggishness in the pass-through from exchange rate changes to import prices, however, we assume that $P_{I, t}$ follows an error correction mechanism. In other words, some fraction ' $\omega_{2}$ ' of the new world price of intermediate goods (expressed in domestic currency terms) feeds through immediately into the domestic prices of these goods. The remainder of the 
adjustment occurs over subsequent periods (we experiment with the pass-through parameters below). ${ }^{7}$

$P_{I, t}=P_{I, t-1}^{1-\omega_{1}}\left(\frac{P_{I^{*}, t}}{e_{t}}\right)^{\omega_{2}}\left(\frac{P_{I^{*}, t-1}}{e_{t-1}}\right)^{\omega_{1}-\omega_{2}}$

When $\omega_{1}=\omega_{2}=1$, the pass-through is full and immediate and PPP holds at all times;

whereas when $0<\omega_{2} \leq \omega_{1}<1$, it is imperfect and spread over time.

\subsubsection{Export Sector Firms}

Firms in the export sector are perfectly competitive. Demand for their goods is given by an export demand function of the following form:

$X_{t}=\left(\frac{P_{F, t}}{P_{X, t} e_{t}}\right)^{\eta} y_{F, t}^{b}$

Where $P_{F, t}$ and $P_{X, t}$ are the foreign and domestic currency prices of the exported good, respectively, and $y_{F, t}$ is world income. This demand function is the same as in McCallum and Nelson (1999).

\subsubsection{Non-Traded Goods Firms}

By definition non-traded goods are produced and consumed only domestically. We assume that the non-traded goods' sector is composed of a continuum of firms indexed by $j \in[0,1]$, each producing a differentiated good. Differentiation implies that non-traded goods producers have market power and can set their prices as a mark-up over marginal unit costs, rather than taking prices as given. In essence, the decision problem for firm $j$ entails choosing

\footnotetext{
${ }^{7}$ This gives us an equation for $P_{I}$ that is similar in form to the goods and services imports deflator equation of the MTMM.
} 
$P_{t}(j), h_{t}(j)$, and $I_{t}(j)$ in order to maximise the utility weighted present value of profits $E_{0} \sum_{t=0}^{\infty} \beta^{t} \Lambda_{t}\left(P_{t}(j) y_{t}(j)-W_{t} h_{t}(j)-P_{I, t} I_{t}(j)\right)$, where $\Lambda_{t}$ represents the marginal utility of one pound. Profit maximisation is subject to the technology constraint $y_{t}(j)=A_{N, t} h_{t}(j)^{\alpha_{N}} I_{t}(j)^{1-\alpha_{N}}-\psi_{1}$, where the term, $\psi_{1}$ is a fixed cost of production. Profit maximisation is also subject to the familiar Blanchard-Kiyotaki constant-elasticity demand function for the non-traded good by domestic consumers:

$$
y_{t}(i)=\left(\frac{P_{N, t}}{P_{t}(j)}\right)^{\theta} c_{N, t}
$$

where $\theta$ is the elasticity of demand for good $z$.

\subsection{Goods' market equilibrium}

Market equilibrium in the non-traded sector implies that all gross output is consumed. Output in the export sector must equal world demand for exports. So the market equilibrium conditions are:

$$
\begin{gathered}
c_{N, t}=y_{N, t} \\
X_{t}=y_{X, t}
\end{gathered}
$$

\subsection{The Transmission Mechanism}

In addition to changes in the interest rate, in our model, both sectors are also affected by changes in the exchange rate. Export demand is directly a function of the exchange rate. And both sectors import intermediate goods from abroad.

However, the exchange rate impacts the two sectors unevenly. This is because, despite the fact that both sectors are affected symmetrically by changes in the domestic price of their intermediate imports, producers in the export sector compete in international markets. By contrast, non-traded goods producers set the price for their output themselves, by applying a 
mark-up on the costs faced to produce it. Thus, the price they charge will not depend directly on the exchange rate, as happens in the export sector, but only indirectly via the impact the exchange rate has on the price of the intermediate imported input.

In summary, there are two channels of monetary transmission in this model. There is a standard interest rate channel, operating via the output gap and thereby onto inflation. In addition, there is a swifter exchange rate channel that directly affects export sector prices; and indirectly affects exports and non-traded goods' prices through changes in the cost of the intermediate imported inputs. But since in our model the export sector is affected both directly and indirectly by the exchange rate, ultimately the burden of adjustment to inflationary shocks (either positive or negative) is borne disproportionately by this sector.

\subsection{The Balance of Payments}

We now turn to the part of the model that relates to international trade, borrowing and lending. To obtain the open arbitrage condition linking interest rate differentials (domestic relative to abroad) with expected changes in the nominal exchange rate, we combine the firstorder conditions for domestic and foreign bonds from the household's optimisation problem. As a first-order approximation, this gives:

$E_{t} \log e_{t+1}-\log e_{t}=i_{f, t}-i_{t}+\zeta_{t}$

This is a conventional uncovered interest parity condition to which we have added a random risk premium term $\left(\zeta_{t}\right)$ that reflects temporary but persistent deviations from UIP, as in Taylor (1993b).

Finally, we focus on the home country's intertemporal budget constraint. We imagine that at time 0 , domestic residents hold a large stock of foreign bonds. ${ }^{8}$ This means that agents domestically can intertemporally save or borrow using foreign assets. As a result it is not necessary for the trade balance to be zero in each period as would have happened if we

\footnotetext{
${ }^{8}$ Large relative to domestic GDP but small relative to the outstanding stock of bonds.
} 
imposed an equilibrium that required no country to be a net creditor or debtor vis-à-vis the rest of the world. In practice, positive holdings of foreign bonds mean that the domestic economy can run a trade deficit in every period financed via the interest payments that it receives on the foreign assets held.

\section{Model Solution and Calibration}

\subsection{Solving the Model}

To solve the model we take the log-linear approximation of each non-linear first-order condition around their respective non-stochastic steady states. The log-linearised equations are presented in the Technical Appendix.

As shown in the technical appendix, the model can be cast in first order form:

$$
\begin{aligned}
& \mathbf{A} E_{t} \mathbf{y}_{t+1}=\mathbf{B} \mathbf{y}_{t}+\mathbf{C} \mathbf{x}_{t}+\varepsilon_{t} \\
& E_{t} \mathbf{x}_{t+1}=\mathbf{P} \mathbf{x}_{t}+\boldsymbol{?}_{t}
\end{aligned}
$$

where $\mathbf{A}$ and $\mathbf{B}$ are $31 \times 31$ matrices, while $\mathbf{C}$ is a $31 \times 8$ matrix. $\mathbf{P}$ is an $8 \times 8$ matrix containing the first order cross-correlation coefficients of the exogenous variables, whose white noise i.i.d. innovations are expressed by the vector ${ }_{t}$.

Let $\mathbf{f}_{t}$ denote the endogenous part of the state vector $\mathbf{y}_{t}$. Then the rational expectations solution to (11)-(12), expressing the vector of endogenous variables $\mathbf{y}_{t}$ as functions of endogenous ( $\left.\mathbf{f}_{t}\right)$ and exogenous $\left(\mathbf{u}_{t}\right)$ states, is equal to:

$$
\begin{aligned}
& \mathbf{z}_{t}=\Xi_{1} \mathbf{f}_{t}+\Xi_{2} \mathbf{u}_{t} \\
& {\left[\begin{array}{c}
\mathbf{f}_{t+1} \\
\mathbf{u}_{t+1}
\end{array}\right]=?\left[\begin{array}{l}
\mathbf{f}_{t} \\
\mathbf{u}_{t}
\end{array}\right]+\left[\begin{array}{c}
0 \\
\boldsymbol{?}_{t}
\end{array}\right]}
\end{aligned}
$$


In this paper we computed this solution using Klein's (1997) algorithm.

\subsection{Calibration}

We calibrated our model so that it matches the key features of UK macroeconomic data. For this purpose, we set the discount factor, $\beta$, in order to imply a steady-state real interest rate of $3.5 \%$, equal to the average ten-year real forward rate derived from the index-linked gilt market in the United Kingdom since these were first issued in March 1983. The steady state inflation rate was set at $2.5 \%$ : the current UK inflation target.

We assumed that foreign inflation on average was equal to the same as domestic inflation on average; that is, $2.5 \%$. This implied that the exchange rate was stationary. We normalised its steady-state value to unity. We also normalised the steady state price of traded goods and the steady state price of intermediate goods (both expressed in foreign currency) to unity.

The weight on leisure vis-à-vis consumption in the utility function, $\delta$, was set to ensure that steady-state hours were equal to 0.3 in the absence of habit formation $\left(\xi_{c}=\xi_{h}=0\right)$.

Though essentially a normalisation, this choice corresponds to an 18 hour day available to be split between work and leisure time and workers, on average, working fifty 40-hour weeks in a year. In order to set the parameter in the utility function reflecting consumer preferences for traded goods vis-à-vis non-traded goods, $\gamma$, we needed data on consumption spending on traded versus non-traded goods. Hence, we equated consumption of non-traded goods with output of non-traded goods and consumption of traded goods as output of traded goods less exports of traded goods. The only reliable data we could obtain on output in current prices by industry was annual and covered only the period 1989 to 1998 . We set $\gamma$ equal to 0.103 , so that the implied constant share of consumption spending on traded versus non-traded goods matched the average value seen in this data. 
Parameters on the production side of the model were calibrated as follows. For the traded sector, we first defined 'manufacturing' and 'transport, storage and communication' (in line with the SIC classification) as traded goods firms. Then, noting that the elasticities of output with respect to labour and imported intermediate inputs must equal the corresponding shares of total revenue, and using data from the Input-Output tables, we obtained a value for the share of labour, $\alpha_{T}$, in the traded goods sector of 0.69 .

Calibration of the equivalent parameter for the non-traded goods sector, $\alpha_{N}$, is more complicated, given our assumption of imperfect competition. We first calibrated the mark-up that non-traded goods sector firms apply to unit marginal costs, using the results of Small (1997) on mark-ups over value added for firms in the service sector (i.e., firms engaged in 'construction', 'distribution, hotels and catering' and 'financial services'). Weighting these mark-ups with the respective shares in value added output, ${ }^{9}$ we obtained a value for the nontraded sector mark-up of 1.183 implying a value for $\theta$ of 5.46. We then obtained a value for the elasticity of non-traded goods output with respect to employment, $\alpha_{N}$, of 0.708 . Finally, we calibrated the fixed costs of adjustment by simply imposing the condition that profits were equal to zero in steady state. The implied value for $\psi_{1}$ turned out to be 0.022 .

We next had to derive series for 'total factor productivity' in each sector. For this purpose, we used quarterly data on gross value added by industry at constant 1995 prices from 1983 onwards (ETAS Table 1.9) and 'workforce jobs' by industry for the same period. ${ }^{10} \mathrm{We}$ calculated our productivity series as:

$\ln A_{Z, t}=\ln y_{Z, t}-\alpha_{Z} \ln h_{Z, t}$

where $Z$ indexes the sector, $y$ is value added and $h$ is workforce jobs. Notice that we have assumed that movements in intermediate inputs are 'small' relative to movements in output and employment in order to equate this measure of $A$ with 'total factor productivity'.

\footnotetext{
${ }^{9}$ We used weights from the 1985 ONS Blue Book.

${ }^{10} \mathrm{We}$ adjusted the workforce jobs series prior to 1995Q3 to take account of a level shift of about 350,000 in total workforce jobs when the series was rebased. To do this, we added to the figure for each industry a share of the 350,000 workers equal to the industry's share in the published total. We combined the output data using the 1995 weights to get real value added for each of our two sectors (where, again, the traded goods sector consisted of 'manufacturing' and 'transport and communications').
} 
After de-trending the two productivity series obtained from (15) - by removing from each a quadratic trend - we derived the stochastic processes for the productivity terms by estimating the following vector autoregressive (VAR) system:

$\left(\begin{array}{c}\hat{A}_{t}^{T} \\ \hat{A}_{t}^{N}\end{array}\right)=\left(\begin{array}{ll}\rho_{T, T} & \rho_{T, N} \\ \rho_{N, T} & \rho_{N, N}\end{array}\right)\left(\begin{array}{c}\hat{A}_{t-1}^{T} \\ \hat{A}_{t-1}^{N}\end{array}\right)+\left(\begin{array}{c}\varepsilon_{T, t} \\ \varepsilon_{N, t}\end{array}\right)$

The disturbances $\varepsilon_{T, t}$ and $\varepsilon_{N, t}$ are independently normally distributed with variances $\sigma_{T}^{2}$ and $\sigma_{N}^{2}$, respectively. Given that the model has zero productivity growth in steady state, $\hat{A}^{Z}$ refers to 'log-deviations of productivity in sector $Z$ from a quadratic trend'. Our estimation results implied that:

$$
\begin{aligned}
& \left(\begin{array}{ll}
\rho_{T, T} & \rho_{T, N} \\
\rho_{N, T} & \rho_{N, N}
\end{array}\right)=\left(\begin{array}{cc}
0.754 & 0.205 \\
0 & 0.877
\end{array}\right) \\
& \sigma_{\varepsilon_{T}}=0.0086 \text { and } \sigma_{\varepsilon_{N}}=0.0062
\end{aligned}
$$

where the zero restriction on the lag of traded goods sector productivity in the equation for non-traded goods sector productivity was imposed and could not be rejected at the $5 \%$ significance level (the LR test of over-identifying restrictions was $\chi^{2}=2.832, p$-value $=0.09$ ).

We then derived processes for the shocks to the one-quarter change in the world price of traded goods and the relative price of imported materials, as well as to foreign interest rates and the exchange rate risk premium. For this purpose, we first constructed a series for the foreign interest rate as a weighted average of three-month Euromarket rates for each of the other G6 countries, using the same weights used to construct sterling ERI. For intermediate goods imports we followed Britton, Larsen and Small (1999) and constructed an index based on the imported components of the Producer Price Index. For the world price of traded goods we used the implicit export price deflator from the National Accounts. We then converted it to foreign currency terms by multiplying by the sterling ERI.

We then estimated the following VAR: 


$$
\left(\begin{array}{c}
i_{f, t}-i_{f} \\
\hat{P}_{I^{*}, t}-\hat{P}_{F, t} \\
\Delta P_{F, t}-\Delta P_{F}
\end{array}\right)=\left(\begin{array}{lll}
\rho_{i_{f}, i_{f}} & \rho_{i_{f}, i_{f}} & \rho_{i_{f}, i_{f}} \\
\rho_{P_{I}, i_{f}} & \rho_{P_{I}, P_{I}} & \rho_{P_{I}, P_{F}} \\
\rho_{P_{F}, i_{f}} & \rho_{P_{F}, P_{I}} & \rho_{P_{F}, P_{F}}
\end{array}\right)\left(\begin{array}{c}
i_{f, t-1}-i_{f} \\
\hat{P}_{I^{*}, t-1}-\hat{P}_{F, t} \\
\Delta P_{F, t-1}-\Delta P_{F}
\end{array}\right)+\left(\begin{array}{c}
\varepsilon_{i_{f}} \\
\varepsilon_{P_{I}} \\
\varepsilon_{P_{F}}
\end{array}\right)
$$

where variables without time subscripts refer to the respective HP trends in the data, and 'hatted' variables represent percentage deviations from HP trends. The disturbances $\varepsilon_{i, t}$, $\varepsilon_{P, t}$ and $\varepsilon_{P_{F}, t}$ are independently normally distributed with variances $\sigma_{i}^{2}, \sigma_{P}^{2}$ and $\sigma_{P_{F}}^{2}$, respectively. Using data over the period 1977 Q3 - 1999 Q2 we obtained the following results:

$$
\begin{aligned}
& \left(\begin{array}{lll}
\rho_{i_{f}, i_{f}} & \rho_{i_{f}, i_{f}} & \rho_{i_{f}, i_{f}} \\
\rho_{P_{I}, i_{f}} & \rho_{P_{I}, P_{I}} & \rho_{P_{I}, P_{F}} \\
\rho_{P_{F}, i_{f}} & \rho_{P_{F}, P_{I}} & \rho_{P_{F}, P_{F}}
\end{array}\right)=\left(\begin{array}{ccc}
0.576 & -0.012 & 0 \\
0 & 0.803 & 0.135 \\
0 & 0 & 0.245
\end{array}\right) \\
& \sigma_{i_{f}}=0.0021, \sigma_{P_{I}}=0.0450 \text { and } \sigma_{P_{F}}=0.0304 .
\end{aligned}
$$

where, again, we imposed all the zero restrictions which could not be rejected at the $5 \%$ significance level (the LR test of over-identifying restrictions was $\chi^{2}=4.39, p$-value $=0.221$ ). We derived a measure of the sterling exchange rate risk premium derived from the Consensus Survey and estimated the following process:

$$
\zeta_{t}=0.261 \zeta_{t-1}+\varepsilon_{\zeta, t}, \sigma_{\zeta}=0.009
$$

We calibrated the shock to world income, $y_{F}$, by estimating the following process:

$$
y_{F, t}=0.841 y_{F, t-1}+\varepsilon_{y_{F}, t}, \sigma_{y_{F}}=0.00279
$$

Finally, in line with McCallum and Nelson (op. cit.) we assumed that the preference shock $v_{t}$ is white noise, and, for simplicity, we set its standard deviation equal to 0.011 as they do for the US. 
The remaining parameters to calibrate were those governing habit persistence in consumption and leisure and the sluggishness of exchange rate passthrough, $\omega_{1}$ and $\omega_{2}$. We set the habit persistence parameters such that the persistence of the output response to shocks in the model was similar to that in the UK data. The values chosen were $\xi_{c}=0.2$ and $\xi_{h}=0.2$. Finally, we set the sluggishness parameters $\omega_{1}$ and $\omega_{2}$ in equation (5) to 0.2 and 0.5 , respectively, implying that one half of exchange rate movements is passed through into the domestic price of intermediate goods within a quarter. ${ }^{11}$

\section{Properties of the model}

To analyse the dynamic properties of the model, we have derived impulse response functions for the key endogenous variables when the model is buffeted with each one of the eight shocks in turn.

Throughout, we closed the model with a policy rule for the nominal interest rate $i_{t}$. The one used here was estimated on UK data over the period 1981Q2-1998Q2, as part of a reduced-form model, alongside another three equations for $(\log )$ aggregate output $\hat{y}_{t}$, (the log of) the annualised log-change in the RPIX index inflation measured in terms of deviations from target $\left(4 \Delta \hat{P}_{t}\right)$ and changes in the (log of the) nominal trade-weighted effective exchange rate $\left(\Delta \ln e_{t}\right)$. The model which is similar to that in Batini and Nelson (1999), also contains two dummies $\left(D E R M_{t}\right.$ and $\left.D 92_{t}\right)$ to capture the years of the UK membership of the ERM and the shift in policy regime which occurred in 1992 Q4.

To identify the shocks, following the methodology in Ericsson, Hendry and Mizon (1998), we re-parameterised the system $Q_{t}=\left[i_{t}, 4 \Delta \hat{P}_{t}, \hat{y}_{t}, \Delta \ln e_{t}\right]$ as the conditional and marginal distributions $i_{t}=f\left(4 \Delta \hat{P}_{t}, \hat{y}_{t}, Q_{t-1}\right)$ and $\left(4 \Delta \hat{P}_{t}, \hat{y}_{t}\right)=\left(Q_{t-1}, \chi\right)$, where $\chi$ is the vector of estimated parameters . In effect, this orthogonalises the shocks, so that the nominal interest rate is not affected by time- $t$ changes in the other variables as would have happened if we

\footnotetext{
${ }^{11}$ This assumption is in line with the single equation properties of the export price equation in the Medium Term Macroeconometric Model (MTMM). However, that equation has richer dynamics than ours, allowing for shocks to the exchange rate to pass through over a longer period of time (8 quarters).
} 
estimated the nominal interest rate as part of a VAR, and identified the shocks via a standard Cholesky decomposition with causal ordering that placed the nominal interest rate last. However, contrary to a VAR estimation approach, this method allows us to derive an estimated equation for the nominal interest rate in which $i_{t}$ depends on contemporaneous values of inflation, output and changes in the exchange rate, rather than on lags of those variables. ${ }^{12}$ The model's estimates are available on request. For convenience, we reproduce here the estimate of the nominal interest rate equation, which we interpret as being the monetary policy reaction function over that period:

$4 i_{t}=c+\kappa_{1} 4 i_{t-1}+\kappa_{2} 4\left(\hat{P}_{t}-\hat{P}_{t-1}\right)+\kappa_{3} \hat{y}_{t}+\kappa_{4}\left(\hat{e}_{t}-\hat{e}_{t-1}\right)+\kappa_{5} D E R M_{t}+\kappa_{6} D 924_{t}+\varepsilon_{i, t}$

where $4 i_{t}$ is the annualised interbank lending rate, and $\varepsilon_{i, t}$ are the equation's estimated residuals. The estimated coefficients (standard errors in parenthesis) are:

$\mathrm{c}=0.0423, \kappa_{1}=0.605, \kappa_{2}=0.406, \kappa_{3}=0.184, \kappa_{4}=-0.065$,
(0.008)
(0.074)
$(---) \quad(0.039)$
$(0.027)$

$\kappa_{5}=-0.014, \kappa_{6}=-0.015$,
(0.003)
(0.004)

with $\mathrm{SE}=0.00821$.

To ensure that this rule was able to stabilise inflation, we restricted the log-run inflation response to the nominal interest rate, i.e. $\kappa_{2} /\left(1-\kappa_{2}\right)$, to be larger than one (setting it equal to 1.01). For this reason, no standard error is reported for that coefficient. The LR test of over-identifying restrictions was unable to reject the null implied by this restriction at a high confidence level $\left[\chi^{2}(1)=0.5032, p\right.$-value $\left.=0.4781\right]$.

\footnotetext{
${ }^{12}$ This method is perhaps preferable to that employed by Rotemberg and Woodford (1997), who obtain a similar dynamic specification of the estimated policy rule by leading the other variables in the vector autoregression model (inflation and output in their case), i.e. estimating a VAR with a vector of endogenous variables equal to $\left[r_{t}, \Delta p_{t+1}, y_{t+1}\right]$. Even if it gives an estimated equation for the interest rate similar to ours, in dynamic terms, their approach also implies meaningless dynamic specifications for the other two variables in the model, where the leads of inflation and output depend only on lags of the interest rate and not also on the level of the interest rate at time $t$.
} 
Since the endogenous variables in the model feature as deviations from their respective longrun values - or enter as first-differences - they are comparable to variables in the loglinearised first-order approximation version of the model.

Figure 1 shows output, (four-quarter) inflation and the nominal interest rate impulse response functions to a unit start shock to the monetary policy rule (22) over 20 periods (quarters). The solid line depicts the analytical model's responses, whereas the dashed line gives the estimated model's responses. Both the estimated and our model's responses broadly agree with conventional wisdom: following a temporary rise in the interest rate, output declines, but ultimately reverts to base; and inflation also goes down (although, in our model, not with a lag with respect to the decline in output as in the estimated model). Note that our estimated inflation equation exhibits no price puzzle (i.e. the finding in many empirically estimated models a rise in the nominal interest rate is associated with a rise — rather than a fall — in the rate of inflation in the periods immediately after the rise). However, we expect there to be rather wide error bands around the estimated model's impulse responses (not shown here) indicating that these effects cannot be estimated with great precision, particularly those on inflation. So, the comparison of the two sets of responses should not be taken too literally.

The top panel of Figure 1 indicates that, in our analytical model, output falls on impact by $0.25 \%$, following an unanticipated one unit rise in the nominal interest rate — the same order of magnitude of that of the estimated model. Also, the policy shock response in the data and in the model appear equally sluggish, with output not returning back to base even after two and a half years following the shock in both cases. But in the data, the trough in output following the shock occurs approximately three quarters later than in our model. The speedier response of output in our model may reflect the particular combination of the effect of exchange rate changes (associated with a shock to the policy rule) on the net exports component of aggregate output in our model and our choice of the degree of habit persistence in consumption. We found that a large habit persistence parameter (close to one) on consumption gives an even more persistent output gap process, but does not delay the impact response. On the other hand, a larger parameter on habit persistence in consumption reduces 
the response of output on impact, as agents who like to smooth consumption, spread their response to a shock over time.
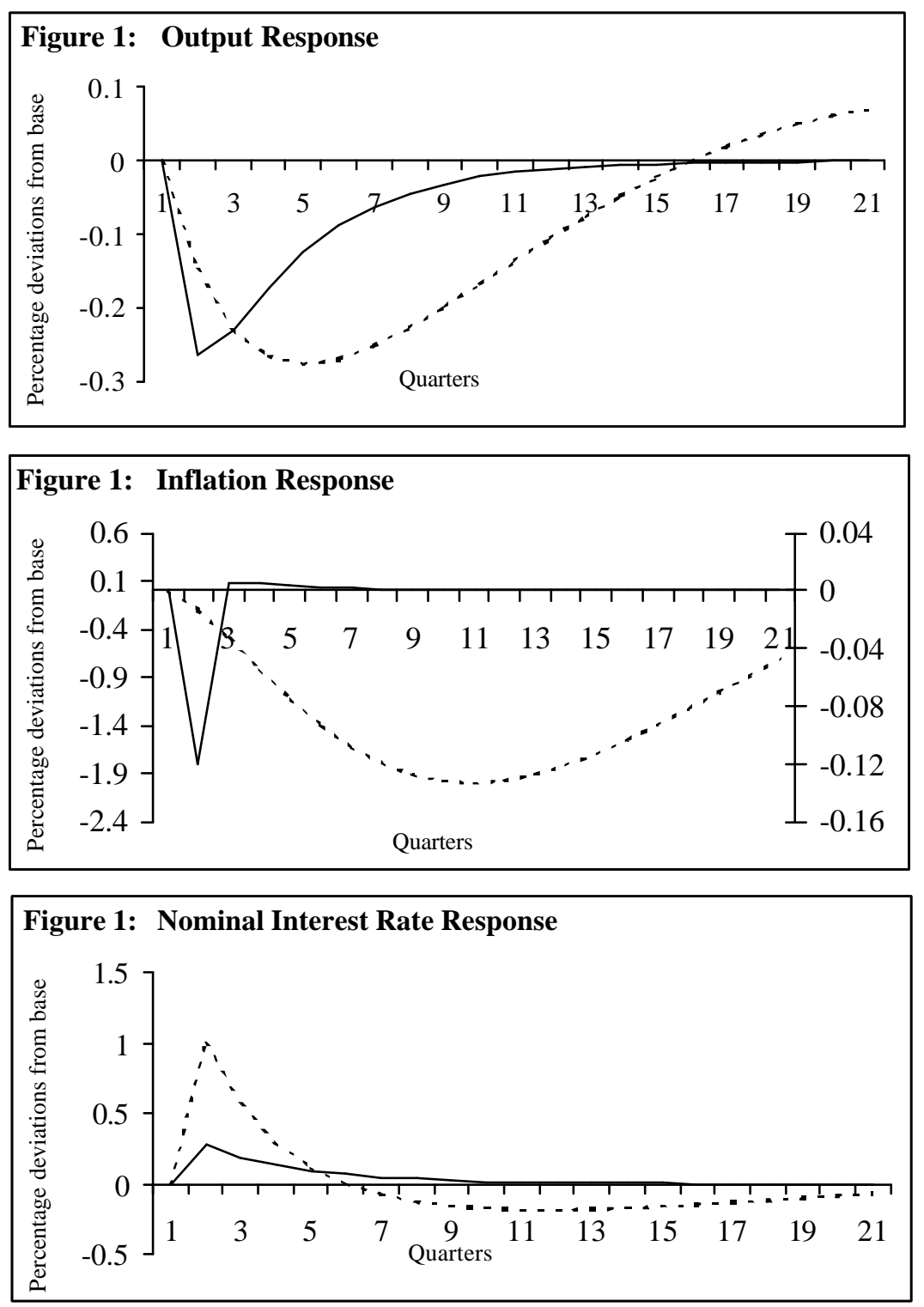

The middle panel of Figure 1 compares ours and the estimated model RPIX inflation responses to the same policy shock. In our model (LHS axis), inflation responds earlier (within the quarter after the shock) and more intensely (almost $-1.8 \%$ versus $-0.12 \%$ in the estimated model, on impact) than in the estimated model. There, inflation touches its nadir around ten quarters after the shock, and returns smoothly back on track over a period of about two to three years. The difference between the two responses probably reflects the fact that our model, even accounting for the built-in persistence, is still a forward-looking, 'jumpier' model, whereas the estimated one is entirely backward-looking. 
The bottom panel of Figure 1 depicts how the (nominal) interest rate responds. While it rises by a full $1 \%$ in the estimated, backward-looking model, the nominal interest rate increases by less than a half of that in our model. There are two reasons why this happens. First, in our model, inflation expected at time $t+1$ ) falls on impact one period after the shock; by contrast, in the estimated model inflation is almost unchanged in the first quarters after the shock. This implies that, in practice, the real interest rate response is harsher on impact (more than double at about $2.2 \%$ ) in our model than in the estimated model (1\%). Second, inflation and output (the feedback variables in the estimated policy rule) are forward-looking in our model; thus the interest rate response will be more muted than in the estimated model, inasmuch as those variables will themselves have already adjusted pre-emptively to the shock.

A second way of evaluating the correspondence between UK data and our model is to look at auto- and cross-correlation functions for key variables as they emerge from the data with the corresponding predictions of the stochastically simulated model. Figure 2 shows this comparison for aggregate output, value added sectoral outputs, RPIX inflation, the nominal interest rate and the real exchange rate. In each of the thirty-six panels, the solid line illustrates the theoretical cross-correlation function and the dashed line the cross-correlation function implied by the estimated model. 
yt
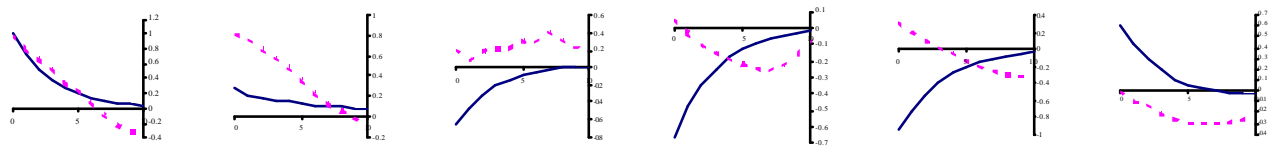

yNt
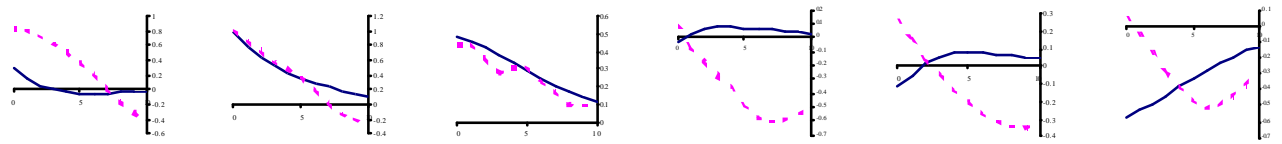

yit
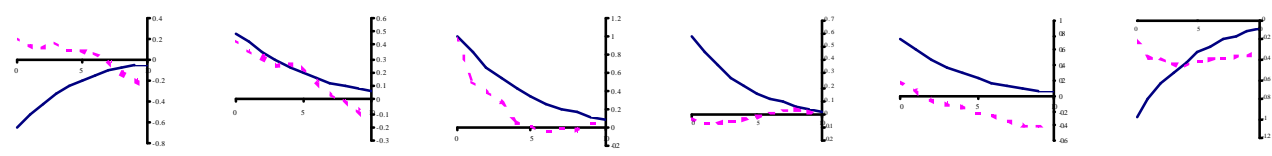

pit
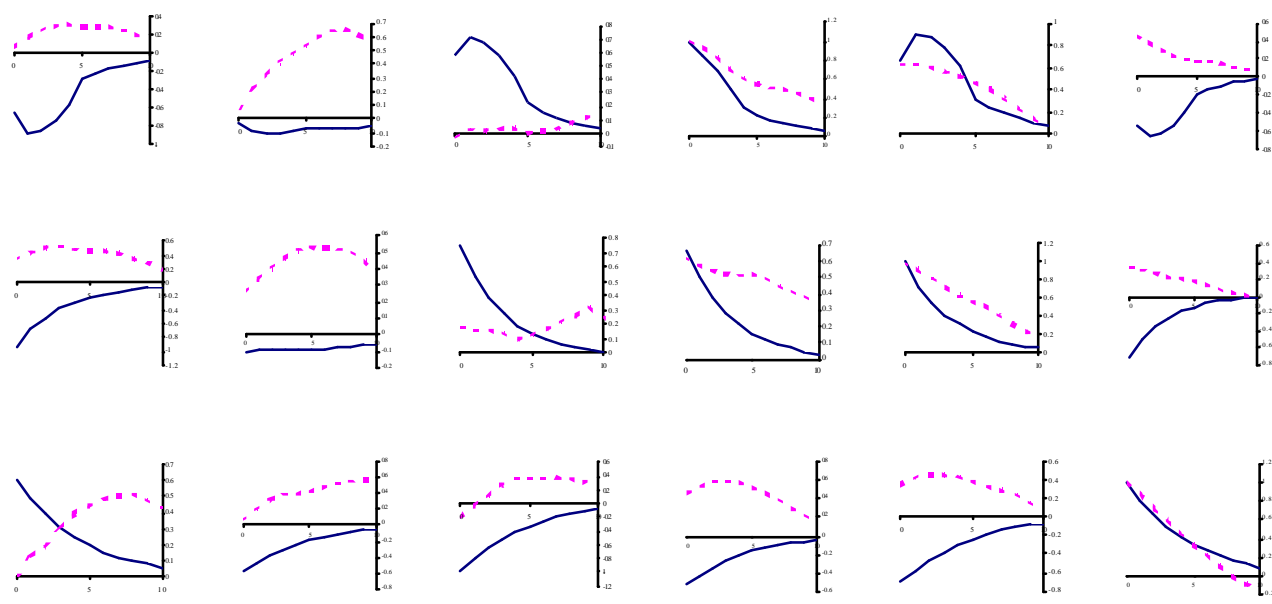

Our model seems to account for the auto-correlations of the data to a reasonable extent (see charts on the diagonal). In particular, our model can in part replicate the degree of persistence of inflation seen in the data, although this is mainly driven by persistence in the exogenous shocks. The model is perhaps less successful at capturing cross-correlation: in particular, the dynamic relationship between value added in the traded sector and the other variables in the panel.

\section{Results: a comparison of alternative simple rules}

In this section we present results from the model when it is closed with alternative monetary policy rules. In what follows we assume that deviations of the nominal interest rate from base 
are a linear function of deviations of endogenous variables (current, lagged or expected) from base. So we consider rules of the form,

$i_{t}=B x_{t}, x_{t} \subseteq\left(z_{t}, z_{t-1}\right)$

where $x$ is the set of feedback variables in the rule and $B$ is a row vector of coefficients. ${ }^{13} \mathrm{~A}$ simple rule therefore consists of two components, the vector of feedback variables, $x$, and the vector of coefficients, $B$. We define generic classes of rules by the $x$ vector, that is, by the set of variables on which they feed back. To carry out the comparison, for each rule we consider two kinds of coefficients vectors, $B$.

First, we look at the rules in their original specification. In this case, the vector of coefficients, $B$, is that suggested initially by the same advocates of those rules [for example, this first group of rules includes a Taylor rule with the original coefficients advocated by Taylor (1993a)]. We call these rules 'non-optimised' because their coefficients are not set optimally for our model. Second, we consider simple 'optimised rules. In this case, the $B$ vectors are those that minimise a given loss function, $L$, for each rule by satisfying:

$\widetilde{B}=\arg \min _{B} L(\pi, y ; B)$

We solve the above minimisation problem by using the simplex search algorithm by Lagarias et al (1997).

As a measure of loss, $L$, we choose the asymptotic loss function associated with each rule, defined as:

$L(\pi, y, B)=\frac{1}{2} A \operatorname{Var}(\pi)+\frac{1}{2} A \operatorname{Var}(y)$

which is a standard quadratic loss function in asymptotic variances (AVar) of inflation deviations from target and output deviations from potential. To obtain the asymptotic

\footnotetext{
${ }^{13}$ Note that by using lag and lead identities within the model, the set of variables that could be included in the rule is large. For example, for the inflation forecast based rule considered below, we include conditional expectations of inflation up to four quarters ahead.
} 
variances for output and inflation that feature in equation (25), we first write the solution of our model as:

$$
z_{t}=?(B) z_{t-1}+\mathbf{F}(B) \mathrm{v}_{t}
$$

where the coefficients in the $\Psi$ and $\Phi$ matrices potentially depend on the rule coefficients, $B$. The asymptotic variance of the state vector, $z$, is given by:

$$
V=\sum_{j=0}^{\infty} \boldsymbol{?}{ }^{j} \mathbf{F} \mathbf{O F}{ }^{\prime} ?^{\prime j}
$$

where $\Omega$ is the covariance matrix of the shocks, $v$. We then compute $V$ via the doubling algorithm of Hansen and Sargent (1999), given the covariance matrix, $\Omega$, calibrated in section 3. The asymptotic variances of output and inflation are given by the relevant elements of $V .{ }^{14}$

\subsection{A battery of rules}

More specifically, we evaluate the relative performance of the following classes of rules:

(i) the estimated policy rule (see section 4);

(ii) a Taylor/Henderson-McKibbin rule;

(iii) an inflation-forecast based (IFB) rule [Batini and Haldane (1999)];

(iv) a MCI-based rule;

(v) an 'open-economy' rule (our BHM rule).

This battery of rules encompasses the mainstay of literature on simple policy rules for both closed and open economies. The estimated rule enables us to assess the remaining rules vis-àvis history, and to infer whether, using these other rules, it may have been possible to do better than historically. We discuss the remaining classes of rules in turn.

The Taylor/Henderson-McKibbin rule

\footnotetext{
${ }^{14}$ This approach is also used in Williams (1999).
} 
This section considers rules of the following form:

$i_{t}=\phi_{p} \pi_{t}+\phi_{y} y_{t}$

where $i_{t}$ denotes the percentage point deviation of the short-term nominal interest rate from steady state, and $\pi_{t}$ and $y_{t}$ are log-deviations of inflation and GDP from base. Rules of this form are often associated with Taylor (1993a) and Henderson and McKibbin (1993). More precisely, Henderson and McKibbin place more weight on the inflation feedback term than Taylor does (i.e. $\phi_{p}=2$ rather than 1.5) and place a weight on the output gap that is four times that in Taylor (i.e. $\phi_{y}=0.5$ rather than 0.125 ). In all cases, rule (28) may be augmented with a lag of the nominal interest rate, to capture interest rate smoothing.

These rules were devised for a closed economy (the US), where the exchange rate channel of monetary transmission has a negligible role in the propagation of monetary impulses. So we would expect them to do relatively badly when compared with rules that account for that channel, or allow for the diverse way in which monetary impulses are transmitted across 'internationally exposed' and 'internationally sheltered' sectors.

\section{The MCI-based rule}

A Monetary Condition Index (MCI) is a weighted average of the domestic interest rate and the (log) exchange rate. A MCI can be expressed in real or nominal terms. Because it has the potential to quantify the degree of tightness (ease) that both the interest rate and the exchange rate exert on the economy, MCIs are often used to measure the stance of monetary policy in an open economy.

A simple rule based on a MCI could then be one that entails adjusting the nominal interest rate to ensure that real monetary conditions are unchanged over time:

$i_{t}=\pi_{t}-\mu q_{t}$ 
where $q_{t}$ is the real exchange rate and $\mu$ is the MCI weight. ${ }^{15}$ Setting $\mu=1 / 3$ - a value consistent with the weights used by the Bank of Canada to construct an MCI — implies that a $3 \%$ appreciation in the real exchange rate is equivalent to a 100 basis points increase in the real interest rate. ${ }^{16}$

In practice, MCIs have been criticised on both empirical and theoretical grounds. ${ }^{17}$ One conceptual shortcoming of a MCI, when used as an operating target, is that different types of shocks have different implications for monetary policy. By construction, a MCI obscures the identification of exchange rate shocks because this requires focusing on movements in the exchange rate and interest rates in isolation, rather than aggregated together [see King (1997)]. By construction, this shortcoming carries over to any MCI-based rule that recommends a level for the interest rate conditioning on the existing level of the exchange rate, when the latter can change for shocks that the central bank may not want to affect monetary conditions. For this reason, we would expect the performance of MCI-based rules to be shock-specific, doing poorly in the face of shocks that affect the exchange rate but do not ask for a compensating change in interest rates (e.g. shocks to the real exchange rate).

\section{Inflation forecast based rules}

Inflation forecast-based (hereafter 'IFB') rules imply that the interest rate should respond to deviations of expected, rather than current, inflation from target. ${ }^{18}$ In the presence of transmission lags, this has the benefit of aligning the policy instrument with the target variable ( i.e. is said to be 'lag-encompassing'), which miminises the output costs of inflation stabilisation

\footnotetext{
${ }^{15}$ We do not consider nominal MCIs as they are likely to perform poorly in our model. The reason is that the level of the nominal exchange rate can shift permanently following a transitory nominal shock. This suggests that a simple nominal MCI rule could lead to instability.

${ }^{16}$ In practice, the actual MCI may be compared with a 'desired' MCI level, MCI*, say. MCI* is the level of monetary conditions compatible with the inflation target and non-inflationary economic growth. In this sense, the desired MCI can be viewed as an open economy extension of Blinder's (1998) concept of a 'neutral rate', an interest rate at which the monetary stance is neither dampening nor stimulating economic activity. In a closed economy, the monetary authority will want the actual nominal rate to depart from its neutral level, whenever the economy is out of equilibrium and vice-versa. In an open economy, the monetary authority may want the actual MCI to deviate from MCI* for the same reason. But it is not entirely clear from the existing literature how MCI-based rules expressed in terms of deviations of actual from desired should be constructed. Basically this is because to do so requires knowledge of how desired monetary conditions will evolve.

${ }^{17}$ See, among others, Ericcson et al (1997).

${ }^{18}$ See Batini and Haldane (op. cit.).
} 
relative to more myopic rules. IFB rules typically do not respond to output deviations from potential: the inflation forecast used in the rules already encompasses the information contained in the current output gap (i.e. they are 'output-encompassing').

Batini and Haldane (op. cit.) compare rules that respond to different horizons of inflation forecasts and assume that policymakers have a tendency to smooth rates. In their small scale macroeconomic model calibrated on UK data, an IFB rule responding to inflation expected 5 quarters ahead with a feedback parameter equal to 5, and an interest rate smoothing parameter equal to 0.5 appears optimal. However, since these rules tend to be highly modelspecific [see Levin, Wieland and Williams (1999a)], we would not expect them to do well in our model for the same choice of horizon and feedback parameters that was efficient in Batini and Haldane (op. cit.). Hence, here we focus on shorter horizons, looking at rule that reacts to expected inflation over the next four periods only. Algebraically, this can be written as:

$$
i_{t}=\lambda_{n r} i_{t-1}+\sum_{j=1}^{4} \lambda_{\pi, 1} E_{t} \pi_{t+j}
$$

This choice of horizons seems more adequate given the small degree of inflation persistence in our model. Note that, in addition, under our IFB rule, the nominal interest rate responds to an average of forecasts, rather than a single forecast. This appears to improve the stabilisation properties of an IFB rule in our model, probably for the reasons pointed out in Levin, Wieland and Williams (1999b) who also find that average-horizon feedback rules outperform single-horizon feedback rules in the FRB/US model.

\section{Our 'open economy simple rule' (BHM)}

Finally, we turn to our proposed rule (BHM). As anticipated, this rule is meant to be a rule for an economy that is open.

Ideally, we want this rule to do two things. First, alongside the standard output gap channel, the rule should also exploit the exchange rate channel of monetary transmission. This should make policy more effective by letting sectors in the economy that are affected unevenly by the 
two major channels of transmission adjust in the most efficient way following a shock. Second, it should do so by augmenting its closed-economy counterpart rules specifications (e.g. Taylor and Henderson and McKibbin) in a parsimonious way. This is because, as in the closed economy case, both on credibility and monitorability grounds, there is a clear merit in having a rule that is simple to compute (e.g. a rule that does not introduce any extra uncertainty in the measurement of its arguments) and that can be easily understood by the public.

We have conducted preliminary experiments on our model to understand what would be the best specification for this rule. We tried to account for the openness of the model economy in three ways. We first replaced aggregate output with output gaps in the two sectors; this takes explicit account of the fact that components of GDP differ in their international exposure. These experiments were unsuccessful. The loss was almost identical to that under closed economy rules (e.g. Taylor/Henderson-McKibbin). In addition, the optimised coefficient on value added in the export sector was negative, probably reflecting the fact that the majority of shocks considered in our model tend to produce a negative correlation between value added in the non-traded and export sectors.

We then experimented with separate coefficients on consumption and the balance of trade. Again, this gave a marginal reduction in loss and a negative coefficient on the trade balance.

Experiments with rules feeding back off exchange rate movements were more fruitful. We tried to include both levels and changes in the exchange rate (deviation from steady state). And we tried contemporaneous and lagged terms in each case. Optimisation of coefficients for both the current or lagged exchange rate level experiments, yielded a positive coefficient on the real exchange rate. This suggests that policy should be tightened in response to an exchange rate appreciation, which contradicts the logic of the MCI.

Eventually, we found that the best specification for an 'open economy' rule is one that accounts for openness in the economy by including changes in the real exchange rate. This can be written as follows:

$i_{t}=\phi_{p} \pi_{t}+\phi_{y} y_{t}+\phi_{y} \Delta q_{t}+\phi_{n r} i_{t-1}$ 
So the BHM rule is similar to a Taylor/Henderson and McKibbin rule because it responds to deviations of current inflation from target and output from potential. But in addition to the usual feedback terms, it also responds to the change in the real exchange rate at time $t$ and includes an interest rate smoothing term. Because this rule explicitly accounts for the exchange rate channel of monetary transmission, we expect it to outperform its closed-economy counterparts. In particular, other things being equal, we expect it to reduce the disparities in the costs of adjustment faced by the two sectors in the economy relative to the closed economy simple rules case.

However, it is important to stress that our preferred specification of this rule should not be interpreted to suggest that the exchange rate should become a target for policy. Rather, it merely suggests that changes in the exchange rate may prove useful if employed to inform changes in the policy instrument because they are good indicators of future inflation and output trends.

\subsection{Results}

Table 1 contains values of the loss function and second order moments of inflation, output, the nominal interest rate, sectoral outputs and the real exchange rate. These are reported for the estimated rule, the Taylor and Henderson and McKibbin rules and for the MCI-based rule with the original weights under our baseline model specification, where habit formation parameters for consumption and leisure are both set to 0.2 and pass-through parameters are set to $\omega_{1}=0.2$ and $\omega_{2}=0.5$. Table 3 , in turn, reports analogous statistics for these rules and for the IFB and BHM rules when coefficients are optimally derived. Table 2 gives the optimised coefficients for each of these rules. Finally, Tables 4 and 5 test the robustness of these results when we change the assumptions on habit formation and exchange rate passthrough in the baseline model.

Table 1: Baseline model, non-optimised coefficients

\begin{tabular}{lrcccccc}
\hline Rule & $L(\pi, y ; B)$ & $\sigma(4 \pi)$ & $\sigma(y)$ & $\sigma(i)$ & $\sigma(y N)$ & $\sigma(y T)$ & $\sigma(q)$ \\
Estimated & 2.6642 & 1.2505 & 1.2432 & 1.1209 & 1.0812 & 4.0328 & 7.3339 \\
Taylor & 1.8547 & 0.9094 & 1.4824 & 1.7690 & 1.1805 & 3.7912 & 6.9971 \\
H-McK & 1.6265 & 0.8464 & 1.4540 & 1.7122 & 1.1341 & 3.7785 & 6.9865 \\
MCI & 39.4365 & 4.4938 & 5.6943 & 4.7914 & 4.1662 & 2.8373 & 6.7566 \\
\hline
\end{tabular}


Table 1 suggests that when coefficients are not optimised, the best performing rule is the Henderson-McKibbin rule. This achieves the lowest loss in the table by responding aggressively to output and inflation deviations. The second best rule is the Taylor rule, which works in the same way as Henderson-McKibbin, but responds less strongly to the feedback variables. The estimated rule comes third. Thanks to its term for interest rate smoothing, this rule responds gradually to inflationary pressures, and thus minimises interest rate and output volatility compared to Taylor/Henderson-McKibbin rules. On the other hand, this makes the estimated rule less successful at stabilising inflation than those rules. Finally, although the simple MCI-based rule ensures the lowest volatility of the real exchange rate and of exports, this comes at the price of poor output and inflation control, implying that the MCI-based rule gives the highest loss.

Table 2 lists the optimal coefficients for the rules presented in table 3 below. The optimisation indicates that Taylor and Henderson-McKibbin rules for the UK economy, as modelled here, require stronger weights on inflation that output than the US. More so, contrary to the wisdom on optimal values of these coefficients for the US [see Taylor (1999)], our model seems to favour a stronger weight on inflation relative to output, even when the policymakers' preferences are symmetric between inflation and output stabilisation. This suggests that a mechanical application of the Taylor and/or Henderson and McKibbin rules in the UK context with coefficients designed for the US is not ideal.

Similarly, for our model economy, the optimal coefficient for the MCI-based rule is indeed much smaller than one third, commonly used in the MCI literature, suggesting that a greater weight than that used in practice should be placed on interest rates than exchange rates when altering monetary conditions.

Table 2: Optimised Coefficients for rules in Table 3 


\begin{tabular}{lll}
\hline Rule & Standard coefficients & Optimised coefficients \\
Taylor & $i_{t}=1.5 \pi_{t}+0.125 y_{t}$ & $i_{t}=4.8 \pi_{t}+2.6 y_{t}$ \\
H-McK & $i_{t}=2 \pi_{t}+0.5 y_{t}$ & $i_{t}-\pi_{t}+0.02 q_{t}=0$ \\
MCI & $i_{t}-\pi_{t}+0.33 q_{t}=0$ & $i_{t}=0.6 i_{t-1}+2.3 E_{t} \pi_{t+1}-0.4 E_{t} \pi_{t+2}$ \\
BH IFB & $i_{t}=0.5 i_{t-1}+0.5 E_{t} \pi_{t+5}$ & $+0.02 E_{t} \pi_{t+3}+0.06 E_{t} \pi_{t+4}$ \\
& & \\
Estd & $i_{t}=0.4 \pi_{t}+0.04 y_{t}-0.02 \Delta e_{t}$ & \\
& $-0.6 i_{t-1}$ & $i_{t}=5.6 \pi_{t}+3.1 y_{t}-0.4 \Delta q_{t}-0.3 i_{t-1}$ \\
BHM & &
\end{tabular}

Table 3 shows that what happens to the performance of the rules when we use the optimal coefficients listed in table 2.

Table 3: Baseline model, optimised coefficients

\begin{tabular}{lccccccc}
\hline Rule & $L(\pi, y ; B)$ & $\sigma(4 \pi)$ & $\sigma(y)$ & $\sigma(i)$ & $\sigma(y N)$ & $\sigma(y T)$ & $\sigma(q)$ \\
Tayl/HMcK & 1.5115 & 0.8033 & 1.4288 & 1.6411 & 1.0904 & 3.7657 & 6.9748 \\
MCI & 3.1207 & 1.4627 & 1.3489 & 2.1385 & 0.8653 & 3.8266 & 7.1083 \\
BH IFB & 2.2958 & 0.4932 & 1.9427 & 0.3227 & 1.3196 & 3.8298 & 7.2093 \\
BHM & 1.4719 & 0.8374 & 1.3874 & 1.8598 & 1.0844 & 3.7014 & 6.8385 \\
\hline
\end{tabular}

The first thing to notice is that Taylor/HendersonMcKibbin and MCI-based rules perform much better than their counterparts with non-optimised coefficients.

When coefficients are optimised, though, rules in the Taylor/Henderson-McKibbin class still outperform the MCI-based rule by ensuring lower exchange rate variability and, hence, lower inflation volatility. Also the IFB rule seems extremely successful at minimising inflation volatility, when coefficients are optimal; a consequence of the fact that under this rule, the interest rate moves only to correct low-frequency changes in inflation. However this policy leads to an insufficient control of output, causing a large loss and making the IFB rule the second worse rule in the set. This suggests that exogenous inflation persistence is not enough for these rules to excel.

According to table 3, the open economy rule appears to dominate all the above rules in our analytical set-up. This should not come as a surprise because, in general, any rule that reacts optimally to more variables in the state vector should do at least as good as rules that react to fewer states. The important fact is that, compared to closed economy and ad hoc open 
economy rival rules, the BHM rule achieves a lower loss and exhibits supplementary properties by adding just a limited number of extra variables — in line with the principle of parsimonious addition.

In more detail, as table 3 illustrates, the BHM rule provides a lower than average variability of inflation when compared to the other rules in table 3. It also reduces the disparity between output sector volatilities in the two sectors, other things being equal. This is because in an open economy, monetary policy can affect aggregate demand either by responding directly to deviations of output from potential via changes in the interest rate or indirectly via changes in the exchange rate. If, as in our model, one sector is more exposed than the other to changes in the exchange rate, a policy that relies entirely on the aggregate output gap channel may be inadequate because it places the burden of adjustment unevenly on the internationally exposed sector. This is mainly a consequence of the different speed at which the two channels operate, with the exchange rate channel — activated by a monetary tightening — penalising the internationally exposed sector first. In this case, responding to both output and to changes in the exchange rate reduces the volatility of output in the export sector - the upshot of which is lower aggregate output volatility. Since the exchange rate also matters for the cost of intermediate inputs paid by the non-traded sector, output volatility in this sector also falls. Importantly, under the BHM rule, the improvement in overall output variability compared to Taylor and Henderson-McKibbin rules, that do not exploit the exchange rate channel, comes at a relatively small price in terms of inflation stability, the trade-off between inflation and output variability being still the best across all rules.

5.3 Sensitivity analysis: changing the assumptions on habit formation and exchange rate passthrough

The optimised coefficients used in the rules in table 2 are derived assuming that the model is calibrated as in our baseline case. These coefficients may no longer be optimal if we change the calibration of the model. So, in this sub-section, we examine the sensitivity of the results in table 3 by re-assessing the performance of the rules - with coefficients unchanged at their baseline-calibration optimised values — varying some of the parameters in the model. 
We focus on two key sets of parameters governing the degree of real and nominal rigidity in the model. These are the habit formation parameters $\left(\xi_{c}, \xi_{h}\right)$, and the parameters on the degree of exchange rate passthrough $\left(\omega_{1}, \omega_{2}\right)$. Statistics summarising the performance of rules in table 2 when these parameters are varied are shown in tables 4 and 5, respectively.

In general, low habit formation and sluggish passthrough imply that real variables are relatively flexible; and vice-versa when habit formation is high and the passthrough is immediate and perfect. As we explain below, this may have implications for the success of each rule at stabilising the economy after a shock.

The upper and lower rows of tables 4 and 5, respectively, illustrate the performance of the rules when there is no habit formation, and the passthrough is sluggish. In both these circumstances, output is relatively flexible as: (i) consumer expenditure can fluctuate considerably from period to period because consumption decisions are entirely forwardlooking; (ii) the price of intermediate imported goods is not flexible and so output has to adjust instead to changes in demand.

In these cases, rules that respond strongly to output like Taylor/Henderson and McKibbin and BHM perform badly (they are 'over-stabilising'). This is because, when output is relatively flexible, aggressive output responses lead to interest rate instability. In turn, this increases real exchange rate and output volatility in the export sector, the upshot of which is higher variability in aggregate output. ${ }^{19}$ For the same reason, rules that do not respond to output like IFB or MCI-based rules, do well with low habits and sluggish passthrough assumptions.

Now consider the remaining rows of tables 4 and 5, i.e. the lower and the upper row in each of those tables, respectively. In this case, either habit formation is assumed to be strong in both consumption and leisure $\left(\xi_{c}=\xi_{h}=0.9\right.$ ) or the passthrough is assumed to be full and immediate $\left(\omega_{1}=\omega_{2}=1\right)$. This is the flip side of the cases postulated above: output is now relatively rigid in both circumstances, as consumption today depends on consumption yesterday or prices adjust swiftly to changes in demand, reducing the need for equilibrating changes in output.

\footnotetext{
${ }^{19}$ These results still hold if we re-optimise coefficients on the BHM rule for the case of zero habit persistence. In this case, the inflation and output feedback coefficients fall, suggesting that it is optimal to be less aggressive when real variables are flexible to adjust. More precisely, the inflation and output coefficients almost halve, converging to about 2.3 and 1.1, respectively. The long-run responses are around 3.1 and 1.4 , respectively.
} 
In these cases rules that respond heavily to output deviations (like Taylor/Henderson and McKibbin or BHM) dominate rules that do not feed back directly on output (as IFB or MCIbased rules). In a world of fast price adjustment and sluggish output dynamics, rules like IFB and MCI with parameters optimised assuming less real and more nominal rigidities, become suddenly 'heavy handed' on inflation either directly (IFB) or via their now excessive feedback on the real exchange rate (MCI-based rule). In fact, the IFB rule destabilises, rather than stabilises, inflation when habit formation is stronger than that for which the rule has been designed; and it produces unstable outcomes under fully flexible prices of intermediate imports.

Table 4: Sensitivity to changes in habit formation parameters

\begin{tabular}{|c|c|c|c|c|c|c|c|}
\hline \multicolumn{8}{|c|}{ Case (a): No habit formation $\left(\xi_{c}=\xi_{h}=0\right)$} \\
\hline Rule & $L(\pi, y ; B)$ & $\sigma(4 \pi)$ & $\sigma(y)$ & $\sigma(i)$ & $\sigma(y N)$ & $\sigma(y T)$ & $\sigma(q)$ \\
\hline Tayl/HMcK & 138.9957 & 0.8228 & 16.5621 & 51.2494 & 9.9919 & 16.7633 & 35.4152 \\
\hline MCI & 3.416 & 1.4587 & 1.5621 & 2.1299 & 1.0529 & 3.8324 & 7.1338 \\
\hline BH IFB & 2.6482 & 0.5101 & 2.0979 & 0.342 & 1.46 & 3.8569 & 7.2573 \\
\hline BHM & 153.5831 & 1.0666 & 17.3768 & 53.5208 & 10.5321 & 17.4719 & 36.895 \\
\hline \multicolumn{8}{|c|}{ Case (b): Strong habit formation $\left(\xi_{c}=\xi_{h}=0.9\right)$} \\
\hline Rule & $L(\pi, y ; B)$ & $\sigma(4 \pi)$ & $\sigma(y)$ & $\sigma(i)$ & $\sigma(y N)$ & $\sigma(y T)$ & $\sigma(q)$ \\
\hline Tayl/HMcK & 0.3542 & 0.5616 & 0.5406 & 2.1122 & 0.652 & 3.2198 & 5.9275 \\
\hline MCI & 2.9949 & 1.6742 & 0.5051 & 2.4508 & 0.6463 & 3.6878 & 6.603 \\
\hline BH IFB & 34.0338 & 3.9791 & 0.7792 & 1.3703 & 1.2389 & 5.1452 & 8.9696 \\
\hline BHM & 0.3678 & 0.6125 & 0.5085 & 2.2842 & 0.6572 & 3.1902 & 5.8523 \\
\hline
\end{tabular}

Table 5: Sensitivity to changes in exchange rate passthrough parameters

\begin{tabular}{|c|c|c|c|c|c|c|c|}
\hline \multicolumn{8}{|c|}{ Case (a): Immediate passthrough $\left(\omega_{1}=\omega_{2}=1\right)$} \\
\hline Rule & $L(\pi, y ; B)$ & $\sigma(4 \pi)$ & $\sigma(y)$ & $\sigma(i)$ & $\sigma(y N)$ & $\sigma(y T)$ & $\sigma(q)$ \\
\hline Tayl/HMcK & 2.4247 & 1.0781 & 1.8173 & 1.7343 & 1.355 & 3.5314 & 6.6383 \\
\hline MCI & 20.721 & 5.6851 & 1.5235 & 6.2106 & 0.8805 & 3.6255 & 7.1786 \\
\hline BH IFB & Unstable & & & & & & \\
\hline BHM & 2.4107 & 1.1487 & 1.7637 & 1.9165 & 1.336 & 3.4959 & 6.5558 \\
\hline \multicolumn{8}{|c|}{ Case (b): Sluggish passthrough $\left(\omega_{1}=0.1, \omega_{2}=0.15\right)$} \\
\hline Rule & $L(\pi, y ; B)$ & $\sigma(4 \pi)$ & $\sigma(y)$ & $\sigma(i)$ & $\sigma(y N)$ & $\sigma(y T)$ & $\sigma(q)$ \\
\hline Tayl/HMcK & 19.8354 & 1.238 & 5.1455 & 30.2986 & 2.348 & 11.0608 & 21.9146 \\
\hline MCI & 3.2377 & 1.325 & 1.3576 & 2.1742 & 0.8681 & 3.902 & 7.2473 \\
\hline BH IFB & 8.0869 & 1.8906 & 1.3533 & 0.2364 & 1.6534 & 4.9214 & 8.7849 \\
\hline BHM & 26.875 & 1.4808 & 5.9259 & 34.1478 & 2.7913 & 12.3615 & 24.4882 \\
\hline
\end{tabular}

5.4 Robustness analysis to individual shocks

As a test of robustness of each rule to individual shocks, we have re-assessed the performance of the rules assuming that the economy was hit by one type of shock at a time. 
In each case, the coefficients in the rules are again those optimally derived for the 'all-shocks' case (shown in table), so this is a test of robustness of the exact rule specification in table $2{ }^{20}$

Results from this experiment are summarised in Table 6. The table suggests that the BHM rule is still the 'best' rule under most shocks. This rule seems to perform particularly well in the face of shocks from overseas. However, the BHM rule is outperformed by its 'closedeconomy' counterparts under productivity shocks to the non-traded and exports sectors. This is in line with the intuition that a rule that responds to exchange rates can be a good guide for policy in the face of some — but not all — shocks. Crucially, however, our rule seems much more robust to different shocks than a naïve MCI-based rule. This is particularly evident for overseas shocks (e.g. foreign interest rate shocks and shocks to the risk premium) and for shocks to productivity in the non-traded sector that are correctly treated as bygones by our rule, but opposed by the MCI-based rule. The IFB rule appears to be the best stabiliser of preference shocks.

A comparison of the losses associated with each shock in turn reveals that the most costly shock by far is that to intermediates prices. This is because this shock not only has a higher variance than other shocks but it is also highly cross-correlated with other overseas shocks. In fact, intermediate prices are a large proportion of unit costs in both sectors. For instance, since non-traded producers set prices as a mark up over unit costs, changes in these prices feed directly through non traded price inflation. On the other hand, shocks to the export sector seem to be relatively unimportant given the size of this sector and the openness of the economy. This is because shocks to this sector are largely absorbed by the price of exports which is not a component of CPI inflation.

By being efficient at stabilising overseas shocks (among which are, notably, shocks to intermediate prices), the BHM rule manages to dominate all other rules in an 'all-shocks' scenario.

\footnotetext{
${ }^{20}$ To perform this test, we have re-derived losses and asymptotic second moments of the variables of interest by setting the variances of the remaining shocks to zero.
} 
Table 6: Single shock analysis of the baseline model

\begin{tabular}{|c|c|c|c|c|c|c|c|}
\hline \multicolumn{8}{|c|}{ Non-traded sector productivity shock } \\
\hline Rule & $L(\pi, y ; B)$ & $\sigma(4 \pi)$ & $\sigma(y)$ & $\sigma(i)$ & $\sigma(y N)$ & $\sigma(y T)$ & $\sigma(q)$ \\
\hline Tayl/HMcK & 0.3705 & 0.4696 & 0.6807 & 0.8007 & 0.8109 & 0.4318 & 1.5186 \\
\hline MCI & 1.395 & 1.2461 & 0.15 & 1.6284 & 0.1169 & 0.3358 & 1.5504 \\
\hline $\mathrm{BH}$ IFB & 0.7736 & 0.3878 & 1.0045 & 0.1521 & 1.0404 & 0.4457 & 1.1392 \\
\hline BHM & 0.3753 & 0.4936 & 0.658 & 0.803 & 0.789 & 0.4177 & 1.4996 \\
\hline \multicolumn{8}{|c|}{ Export sector productivity shock } \\
\hline Rule & $L(\pi, y ; B)$ & $\sigma(4 \pi)$ & $\sigma(y)$ & $\sigma(i)$ & $\sigma(y N)$ & $\sigma(y T)$ & $\sigma(q)$ \\
\hline Tayl/HMcK & 0.0022 & 0.0342 & 0.0516 & 0.074 & 0.0225 & 0.71 & 0.0893 \\
\hline MCI & 0.0043 & 0.0523 & 0.0402 & 0.0816 & 0.0084 & 0.6989 & 0.0807 \\
\hline BH IFB & 0.0093 & 0.0634 & 0.0542 & 0.0022 & 0.0129 & 0.6745 & 0.0146 \\
\hline BHM & 0.0023 & 0.036 & 0.0503 & 0.0738 & 0.0215 & 0.7089 & 0.0879 \\
\hline \multicolumn{8}{|c|}{ Overseas interest rate shock } \\
\hline Rule & $L(\pi, y ; B)$ & $\sigma(4 \pi)$ & $\sigma(y)$ & $\sigma(i)$ & $\sigma(y N)$ & $\sigma(y T)$ & $\sigma(q)$ \\
\hline Tayl/HMcK & 0.0081 & 0.067 & 0.0903 & 0.2042 & 0.0396 & 0.1529 & 0.3058 \\
\hline MCI & 0.0354 & 0.1559 & 0.0228 & 0.271 & 0.0248 & 0.1918 & 0.3499 \\
\hline BH IFB & 0.0193 & 0.0904 & 0.1159 & 0.0511 & 0.0461 & 0.2142 & 0.4259 \\
\hline BHM & 0.0073 & 0.071 & 0.0811 & 0.2368 & 0.0358 & 0.1429 & 0.2841 \\
\hline \multicolumn{8}{|c|}{ Foreign exchange risk premium shock } \\
\hline Rule & $L(\pi, y ; B)$ & $\sigma(4 \pi)$ & $\sigma(y)$ & $\sigma(i)$ & $\sigma(y N)$ & $\sigma(y T)$ & $\sigma(q)$ \\
\hline Tayl/HMcK & 0.0255 & 0.1177 & 0.0969 & 0.7379 & 0.0363 & 0.2159 & 0.4213 \\
\hline MCI & 0.2348 & 0.3055 & 0.0254 & 0.6953 & 0.0601 & 0.3579 & 0.6466 \\
\hline BH IFB & 0.0507 & 0.0794 & 0.2964 & 0.0442 & 0.1488 & 0.4046 & 0.8446 \\
\hline BHM & 0.0211 & 0.1279 & 0.0648 & 0.8837 & 0.0385 & 0.1729 & 0.3268 \\
\hline \multicolumn{8}{|c|}{ Foreign inflation shock } \\
\hline Rule & $L(\pi, y ; B)$ & $\sigma(4 \pi)$ & $\sigma(y)$ & $\sigma(i)$ & $\sigma(y N)$ & $\sigma(y T)$ & $\sigma(q)$ \\
\hline Tayl/HMcK & 0.0149 & 0.0898 & 0.07 & 0.584 & 0.0263 & 0.1608 & 0.3128 \\
\hline MCI & 0.141 & 0.2336 & 0.0191 & 0.5387 & 0.0463 & 0.2736 & 0.4941 \\
\hline BH IFB & 0.0303 & 0.0591 & 0.2304 & 0.0247 & 0.116 & 0.313 & 0.6543 \\
\hline $\mathrm{BHM}$ & 0.0124 & 0.0978 & 0.0454 & 0.7004 & 0.0298 & 0.1267 & 0.2378 \\
\hline \multicolumn{8}{|c|}{ Imported intermediates price shock } \\
\hline Rule & $L(\pi, y ; B)$ & $\sigma(4 \pi)$ & $\sigma(y)$ & $\sigma(i)$ & $\sigma(y N)$ & $\sigma(y T)$ & $\sigma(q)$ \\
\hline Tayl/HMcK & 0.6257 & 0.5916 & 0.8871 & 1.0076 & 0.1805 & 3.6202 & 6.7611 \\
\hline MCI & 0.7429 & 0.6292 & 0.879 & 0.9796 & 0.1151 & 3.6823 & 6.8719 \\
\hline BH IFB & 1.0399 & 0.2629 & 1.3687 & 0.269 & 0.3015 & 3.6707 & 7.0232 \\
\hline $\mathrm{BHM}$ & 0.5968 & 0.6147 & 0.8504 & 1.1811 & 0.2437 & 3.56 & 6.6357 \\
\hline \multicolumn{8}{|c|}{ Preference shock } \\
\hline Rule & $L(\pi, y ; B)$ & $\sigma(4 \pi)$ & $\sigma(y)$ & $\sigma(i)$ & $\sigma(y N)$ & $\sigma(y T)$ & $\sigma(q)$ \\
\hline Tayl/HMcK & 0.4634 & 0.216 & 0.8744 & 0.3194 & 0.7032 & 0.2681 & 0.4982 \\
\hline MCI & 0.5654 & 0.12 & 1.0102 & 0.3245 & 0.8458 & 0.1425 & 0.3277 \\
\hline BH IFB & 0.3705 & 0.0351 & 0.8555 & 0.0588 & 0.7277 & 0.0826 & 0.1626 \\
\hline $\mathrm{BHM}$ & 0.4556 & 0.2166 & 0.8673 & 0.2902 & 0.6998 & 0.2588 & 0.4781 \\
\hline \multicolumn{8}{|c|}{ World demand shock } \\
\hline Rule & $L(\pi, y ; B)$ & $\sigma(4 \pi)$ & $\sigma(y)$ & $\sigma(i)$ & $\sigma(y N)$ & $\sigma(y T)$ & $\sigma(q)$ \\
\hline Tayl/HMcK & 0.0011 & 0.0241 & 0.0364 & 0.0478 & 0.0151 & 0.4647 & 0.0582 \\
\hline MCI & 0.0019 & 0.0364 & 0.0278 & 0.0542 & 0.0052 & 0.4719 & 0.0531 \\
\hline BH IFB & 0.0023 & 0.0218 & 0.0526 & 0.0034 & 0.0232 & 0.4745 & 0.0263 \\
\hline BHM & 0.0011 & 0.0254 & 0.0354 & 0.0478 & 0.0144 & 0.4654 & 0.0574 \\
\hline
\end{tabular}




\section{Conclusions}

Existing closed economy rules like those advocated by Taylor (1993a) and Henderson and McKibbin (1993) may not account for the exchange rate channel of monetary transmission because they only respond to inflation deviations from target and output deviations from potential. In this paper we have explored alternative simple monetary policy rules for an economy that is open like the UK. This entailed augmenting parsimoniously existing rules for closed economies with terms that explicitly account for the exchange rate transmission channel.

We concluded that a good rule in this respect is one that responds to changes in the real exchange rate in addition to output and inflation. This rule is associated with a lower than average variability of inflation when compared to the alternative closed economy rules. Relative to those, it also appears to reduce the disparity between output sector volatilities in the two sectors, other things being equal.

In general, our rule seems to dominate inflation forecast based rules, probably a consequence of the low degree of endogenous inflation persistence in our model economy. Importantly, our rule outperforms existing rules devised for open economies like MCI-based rules. Because these tie the level of the interest rate to the level of the exchange rate, typically exchange rate volatility under these rules is large. This in turn leads to high inflation volatility and large losses.

Crucially, our rule seems much more robust to different shocks than a naïve MCI-based rule. This is particularly evident for overseas shocks (e.g. foreign interest rate shocks and shocks to the risk premium) and for shocks to productivity in the non-traded sector that are correctly treated as bygones by our rule, but opposed by the MCI-based rule.

However, our results should not be interpreted to suggest that the exchange rate should become a target for policy. Rather, they only suggest that changes in the exchange rate may prove useful if employed to inform changes in the policy instrument because they are good indicators of future inflation and output trends. 


\section{References}

Ball, L (1994), 'Credible disinflation with staggered price-setting', American Economic Review, 84(1), pages 282-89.

Batini, N and Haldane, A G (1999), 'Forward-looking rules for monetary policy', Bank of England Working Paper, Number 91.

Blinder, A S (1998), Central banking in theory and practice, Lionel Robbins Lectures, Cambridge and London: MIT Press.

Boldrin, M, Christiano, L J and Fisher, J D M (1999), 'Habit persistence, asset returns and the business cycle', mimeo.

Britton, E, Larsen, J D J, and Small, I (1999), 'Imperfect competition and the dynamics of mark-ups', Bank of England Working Paper, Number 110.

Bryant, RC, Hooper, $P$ and Mann, C (1993), Evaluating Policy Regimes, Washington DC, The Brooking Institution.

Buiter, W H and Miller, M (1982), 'Real exchange rate overshooting and the output cost of bringing down inflation', European Economic Review, 18, pages 85-123.

Carrol, C D, Overland, J, and Weil, D N (1995), 'Saving and Growth with Habit Formation', FEDS Working Paper \# 95-42.

Correia, I, Neves, J C and Rebelo, S (1994), 'Business Cycles in a Small Open Economy', Centre for Economic Policy Research Discussion Paper, Number 996.

Dixit, A V and Stiglitz, J E (1977), 'Monopolistic Competition and Optimum Product Diversity', American Economic Review, 67(3), pages 297-308.

Fuhrer, J C (2000) , ‘An Optimisation-Based Model for Monetary Policy Analysis: Can Habit Formation Help?', American Economic Review, forthcoming.

Hansen, L P and Sargent, T J (1998), Recursive Linear Models of Dynamic Economies, Chicago: University of Chicago Press.

Henderson, D W and McKibbin, W J (1993), 'A comparison of some basic monetary policy regimes for open economies: implications of different degrees of instrument adjustment and wage persistence', Carnegie-Rochester Conference Series on Public Policy, 39, pages 221-317.

King, M A, (1997), 'Monetary Policy and the Exchange Rate', BEQB, May 1997, pages 225-7. 
Klein, P (1997), 'Using the generalized Schur form to solve a system of linear expectational difference equations', mimeo.

Lagarias, J C, Reeds, J A, Wright, M H and Wright, P E (1997), 'Convergence properties of the Nelder-Mead simplex algorithm in low dimensions', to appear in the SIAM Journal of Optimization.

Levin, A, Wieland, V and Williams, J C (1998), 'Robustness of simple monetary policy rules under model uncertainty', Federal Reserve Board of Governors Finance and Economics Discussion Paper, Number 1998-45.

McCallum, B and Nelson, E (1999), 'Nominal income targeting in an open-economy optimizing model', Journal of Monetary Economics, 43(3), pages 553-78.

Obstfeld, M and Rogoff, K (1996), Foundations of international macroeconomics, Cambridge, MA: MIT press.

Rotemberg, J J and Woodford, M (1997), 'An optimisation-based econometric framework for the evaluation of monetary policy', NBER Macroeconomics Annual 1997, Cambridge, MA: MIT Press, pages 297-346.

Small, I (1997), 'The cyclicality of mark-ups and profit margins: some evidence for manufacturing and services', Bank of England Working Paper, Number 72.

Svensson, L E and van Wijnbergen, S (1989), 'Excess capacity, monopolistic competition, and international transmission of monetary disturbances', Economic Journal, 99(397), pages 785-805.

Taylor, J B (1993a), 'Discretion versus Policy Rules in Practice', Carnegie Rochester Conference Series on Public Policy, 39, pages 195-214.

Taylor, J B (1993b), Macroeconomic Policy in a World Economy, New York, W.W. Norton.

Taylor, J B (Ed) (1999), Monetary Policy Rules, Chicago and London: University of Chicago Press.

Williams, J C (1999), 'Simple rules for monetary policy', Federal Reserve Board of Governors Finance and Economics Discussion Paper, Number 1999-12. 